\title{
Integrasi Pendidikan Karakter dalam Pembelajaran Akidah Akhlak
}

\author{
Harpan Reski Mulia ${ }^{1}$ \\ 1MIN 11 Aceh Tenggara, Banda Aceh, \\ harpanreskimulia@gmail.com
}

\begin{tabular}{|c|c|}
\hline & Abstract \\
\hline \multirow[t]{2}{*}{$\begin{array}{l}\text { Keywords: } \\
\text { Akidah akhlak; } \\
\text { integration; } \\
\text { education of } \\
\text { character; } \\
\text { learning } \\
\text { process. }\end{array}$} & $\begin{array}{l}\text { In recent time, character education is viewed as important thing in } \\
\text { education. It has been applied in all education institutions. In this } \\
\text { writing, the approach of integration theory is used to analyze the } \\
\text { integration of character education in learning process of study at } \\
\text { school, especially the learning process inAkidah Akhlak. Because, } \\
\text { the akidah akhlak has been the value of Islam to teach to the } \\
\text { students. The objective of this research is to know the process of } \\
\text { integration of character education in learning process of Akidah } \\
\text { Akhlak. This research used descriptive qualitative method by } \\
\text { using phenomenological approach, the phenomenology approach } \\
\text { used to understanding the phenomenon by looking directly how } \\
\text { the integration of character education in learning process of } \\
\text { Akidah Akhlak which is being taught by teachers in class rooms of } \\
\text { MIN } 11 \text { Aceh Tenggara, based on observation, interview and } \\
\text { documentation. The result of this research shows that the } \\
\text { integration of character education in learning process of Akidah } \\
\text { Akhlak through: the core of competence, the objectives of study } \\
\text { and the learning method process which are used by akidah } \\
\text { akhlak's teachers. }\end{array}$ \\
\hline & Abstrak: \\
\hline $\begin{array}{l}\text { Kata Kunci: } \\
\text { Akidah akhlak; } \\
\text { integrasi; pendidikan } \\
\text { karakter; proses } \\
\text { pembelajaran. }\end{array}$ & $\begin{array}{l}\text { Pendidikan karakter akhir-akhir ini menjadi perhatian khusus di } \\
\text { dunia pendidikan, bahkan menjadi kewajiban pada semua } \\
\text { lembaga pendidikan menyelenggarakan pendidikan karakter. } \\
\text { Dalam artikel ini, peneliti mendekati pendidikan karakter melalui } \\
\text { teori integrasi, dengan menganalisis integrasi pendidikan karakter } \\
\text { di dalam disiplin mata pelajaran, secara khusus mata pelajaran } \\
\text { Akidah Akhlak. Karena, Akidah Akhlak harus mempunyai andil } \\
\text { besar dalam penyadaran nilai-nilai agama Islam kepada peserta } \\
\text { didik. Tujuan dari penelitian ini adalah untuk mengetahui proses } \\
\text { integrasi pendidikan karakter dalam proses pembelajaran akidah } \\
\text { akhlak. Dengan menggunakan metode kualitatif deskriptif } \\
\text { melalui pendekatan fenomenologi, peneliti berupaya memahami } \\
\text { secara langsung proses integrasi pendidikan karakter dalam } \\
\text { pembelajaran akidah akhlak, yang dilakukan oleh guru mata }\end{array}$ \\
\hline
\end{tabular}


pelajaran Akidah Akhlak di MIN 11 Aceh Tenggara. Observasi, wawancara, dan dokumentasimerupakan metode pengumpulan data, yang darinya peneliti menemukan bahwa integrasi pendidikan karakter dalam pembelajaran Akidah Akhlak dapat melalui kompetensi inti, tujuan pembelajaran,serta metode pembelajaran yang digunakan guru mata pelajaran Akidah Akhlak.

\begin{tabular}{ccc}
\hline \hline Received : 11 Maret 2020 & Revised: 06 Mei 2020 & Accepted: 16 Juni 2020 \\
\hline $\begin{array}{c}\text { () TadrisJurnal Pendidikan Islam } \\
\text { Institut Agama Islam Negeri Madura, Indonesia }\end{array}$ & http://doi.org/10.19105/tjpi. & This is an open access article under the CC-BY-NC license \\
\hline \hline
\end{tabular}

\section{Pendahuluan}

Pendidikan sejatinya adalah proses memanusiakan manusia, hal ini dimaksudkan karena manusia dalam mencapai kemulian tentulah harus melalui pendidikan. Di Indonesia, tujuan pendidikan dirumuskan dalam suatu perundangundangan atau peraturan. Poin penting dari tujuan pendidikan di Indonesia adalah terbentuknya akhlak atau karakter peserta didik. ${ }^{1}$

Dewasa ini, sorotan utama pendidikan di Indonesia adalah akhlak siswa, karena dekadensi moral yang semakin ambruk. Krisis tersebut antara lain tawuran antar pelajar, pemerasan/kekerasan (bullying), penyalahgunaan obatobatan, pornografi, kebiasaan mencontek dan lain sebagainya, semua itu merupakan masalah-masalah sosial dan hingga saat ini belum dapat diatasi secara tuntas, padahal sejatinya salah satu aspek yang diutamakan dalam proses pembelajaran di Indonesia adalah membangun mental positif dalam berbagai dimensi yang tergambar pada undang-undang nomor 20 tahun 2003 tentang sistem pendidikan nasional. ${ }^{2}$

Ketika lembaga pendidikan menjadi harapan semua orang, untuk membina karakter peserta didik, maka tidak bisa tidak, pendidikan harus lebih progresif dalam memberikan ekstra perhatian dalam pembinaan karakter tersebut. Dilain pihak, selain pendidikan karakter ini, kurikulum yang diembankan kepada sekolah juga berupa pembinaan dalam ranah afektif dan psikomotorik. Artinya, pendidikan yang diharapkan pada saat sekarang ini adalah pendidikan yang terintegrasi pada tiga ranah tersebut.

Pendidikan yang bersifat tektual, pada mata pelajaran pendidikan moral dan budi pekerti di sekolah, dan/atau akidah akhlak di madarasah, menjadikan penanaman karakter ini menjadi tidak efektif. ${ }^{3}$ Padahal seogianya, mata pelajaran yang berkenaan dengan penanaman karakter harus lebih berupa kontekstual, terkhusus lagi pada jenjang pendidikan Islam, di semua tingkatan (Madrasah Ibtidaiyah, Madrasah Tsanawiyah, Madrasah Aliyah) satu mata pelajaran khusus terkait pembinaan karakter, yaitu Akidah Akhlak. Selain itu, pendidikan Islam

\footnotetext{
${ }^{1}$ Seperti yang tertuang dalam Permen No. 57 Tahun 2015, Bab VIII, Pasal 24 bahwa pada poin "b" peserta didik dinyatakan lulus dari Satuan Pendidikan setelah memperoleh nilai sikap / perilaku minimal baik. Kementerian Pendidikan dan Kebudayaan, "Badan Penelitian Dan Pengembangan | Kementerian Pendidikan Dan Kebudayaan," accessed January 7, 2019, http://litbang.kemdikbud.go.id/content/02_\%20SKL\%20MAPEL\%20SD-MI.pdf.

${ }^{2}$ Lihat: BAB 1 Pasal 1 UU No. 20 Th 2003 Tentang Sistem Pendidikan Nasional "UU20-2003Sisdiknas.Pdf," accessed May 4, 2020, https://www.unpad.ac.id/wpcontent/uploads/2012/10/UU20-2003-Sisdiknas.pdf.

${ }^{3}$ Darmiyati Zuchdi, Zuhddan Kun Prasetya, and Muhsinatun Siasah Masruri, Model Pendidikan Karakter: Terintegrasi Dalam Pembelajaran Dan Pengembangan Kultur Sekolah (Yogyakarta: Multi Presindo, 2013), 1.
} 
harus menomor satukan sikap/moral daripada intelektual dan tidak ada kegiatan yang lebih didahului oleh afektifitasasi keimanan kepada Tuhan. ${ }^{4}$

Jika ditilik lebih lanjut, pelajaran Akidah Akhlak dan pendidikan karakter misi yang sama, sebagaimana akhlak menurut Muhammad Al-Hufy yakni kemauan yang kuat untuk melakukan kebaikan secara berulang-ulang sehingga menjadi kebiasaan. ${ }^{5}$ Adapun pendidikan karakter adalah proses penanaman kebiasaan yang baik, agar menjadi kebiasaan (habit) dalam kehidupan seharihari. ${ }^{6}$ Dengan demikian, maka perlu perhatian yang lebih besar pada pelajaran akidah akhlak, agar mata pelajaran ini lebih optimal dalam menanamkan pendidikan karakter bagi peserta didik dan juga sebagai out-put yang diharapkan dari mata pelajaran akidah aklak sendiri.

Salah satu upaya optimalisasi penanaman pendidikan karakter ini adalah dengan mengintegrasikan dalam pelajaran akidah akhlak. Sebagaimana dalam berbagai mata pelajaran, pendidikan karakter dapat diintegrasikan seperti pada pelajaran IImu Pengetahuan Sosial, ${ }^{7}$ Pendidikan Kewarganegaraan, ${ }^{8}$ IImu Pengetahuan Alam, ${ }^{9}$ Pelajaaran Bahasa, ${ }^{10}$ Pelajaran Bahasa Jerman, ${ }^{11}$ dan lain sebagainya, demikian juga pada pelajaran akhidah akhlak harus diupayakan. Ada beberapa alasan integralisasi ini harus dilakukan, pertama menguatkan akidah peserta didik pada zaman 4.0 ini, sangat diperlukan. ${ }^{12}$ Kedua, dengan mengintegrasikan dalam pelajaran akhlak, maka siswa beraklak kepada Allah, sesama manusia, dan kepada diri sendiri. ${ }^{13}$

Dari uraian diatas, maka perlu adanya sebuah usaha dalam mengartikulasikan pendidikan karakter baik secara konseptual maupun praktis pada mata pelajaran akidah akhlak, supaya pendidikan karakter tidak selalu hanya bermain pada ranah kognitif, namun juga dapat mencapai pada ranah afektif dan psikomotor atau diaplikasikan dalam kehidupan nyata peserta didik. Untuk melihat upaya guru akidah akhlak dalam mengintegrasikan pendidikan karakter dalam pelajaran akidah akhlak, metode yang digunakan dalam penelitian ini adalah deskriptif kualitatif. Sebagaimana penelitian kualitatif bermaksud untuk memahami fenomena tentang apa yang dialami oleh subjek penelitian misalnya

\footnotetext{
${ }^{4}$ Dja'far Siddik, Konsep Dasar IImu Pendidikan Islam, Edisi Revisi, Cet. 1 (Bandung: Citapustaka Media Perintis, 2011), 49.

${ }^{5}$ Haedar Nashir, Pendidikan Karakter Berbasis Agama Dan Budaya (Yogyakarta: Multi Presindo, 2013), 23.

${ }^{6}$ Agustino Hermino, Manajemen Kurikulum berbasis Karakter: Konsep, Pendekatan, dan Aplikasi (Bandung: Alfabeta, 2014), 159.

'Rifki Afandi, "Integrasi Pendidikan Karakter Dalam Pembelajaran IPS Di Sekolah Dasar," PEDAGOGIA: Jurnal Pendidikan 1, no. 1 (February 1, 2011): 85-98, https://doi.org/10.21070/pedagogia.v1i1.32.

${ }^{8}$ Puspa Dianti, "Integrasi Pendidikan Karakter Dalam Pembelajaran Pendidikan Kewarganegaraan Untuk Mengembangkan Karakter Siswa," Jurnal Pendidikan IImu Sosial 23, no. 1 (2014), https://doi.org/10.17509/jpis.v23i1.2062.

${ }^{9}$ M. Khusniati, "Pendidikan Karakter Melalui Pembelajaran IPA," Jurnal Pendidikan IPA Indonesia 1, no. 2 (2012), https://doi.org/10.15294/jpii.v1i2.2140.

${ }^{10}$ Beniati Lestyarini, "Penumbuhan Semangat Kebangsaan Untuk Memperkuat Karakter Indonesia Melalui Pembelajaran Bahasa," Jurnal Pendidikan Karakter 0, no. 3 (2012): 340-54, https://doi.org/10.21831/jpk.v0i3.1250.

${ }^{11}$ Sulis Triyono, "Pengintegrasian Pendidikan Karakter dalam Pembelajaran Bahasa Jerman," Jurnal Pendidikan Karakter 0, no. 3 (2012): 269-79, https://doi.org/10.21831/jpk.v0i3.1250.

${ }^{12}$ Zaini Zaini and Roni Ramlan, "Penguatan Pendidikan Aqidah Anak Dari Penyimpangan Budaya Online," TADRIS: Jurnal Pendidikan Islam 14, no. 2 (December 26, 2019): 201-214, https://doi.org/10.19105/tjpi.v14i2.2736.

${ }^{13}$ Buhari Pamilangan, "Integrasi Pendidikan Karakter Dalam Pembelajaran Aqidah Akhlak," Istiqra : Jurnal Pendidikan Dan Pemikiran Islam 6, no. 1 (2018), https://www.umpar.ac.id/jurnal/index.php/istiqra/article/view/467.
} 
perilaku, persepsi, motivasi, tindakan, dll., secara holistik. ${ }^{14}$ Adapun locus penelitian ini adalah Madrasah Ibtidaiyah Negeri 11 Aceh Tenggara, yaitu dengan wawancara, observasi, dan dokumentasi, data kemudia dianalisis dengan teknik Miles dan Huberman berupa, reduksi data, penyajian data, dan membuat kesimpulan/verifikasi. ${ }^{15}$

\section{Pebahasan}

\section{A. Pendidikan Karekter dan Pembelajaran Akidah Akhlak}

1) Pendidikan Karakter dan Lembaga Pendidikan

Sekitar tahun 1900-an, terminologi pendidikan karakter mulai merebak dalam dunia pendidikan, terutama sejak luching buku Thomas Lickona yang berjudul "The Return of Character Education", kemudian disusul bukunya yang berjudul "Educating For Character: How Our School Can Teach Resfect and Responsibility". Karakter atau "character"secara etomologi berasal dari bahasa Yunani "charessein" yang berarti mengukir corak yang tetap dan tidak dapat terhapus. Adapun secara terminologi karakter berarti perpaduan dari segala tabiat manusia yang bersifat tetap sehingga menjadi tanda khusus untuk membedakan orang yang satu dengan yang lainnya. ${ }^{16}$

Dari pengertian diatas, maka pendidikan karakter yang dilaksanakan disekolah, secara sederhana dapat diartikan sebagai usaha yang dilakukan oleh semua komponen sekolah untuk menanamkan perilakuperilaku baik kepada peserta didik, sehingga menjadi suatu kebiasaan yang tetap. Seperti yang dikemukakan oleh Zubaedi, bahwa pendidikan karakter di sekolah adalah "the delibrate us of all dimensions of school life to foster development". ${ }^{17}$ Sejalan dengan Zubaedi, Agus Wibowo lebih detail memberikan gambaran tujuan pendidikan karakter pada lembaga pendidikan, yakni sebagai usaha untuk menanamkan dan mengembangkan karekater-karakter luhur kepada anak didik, sehingga mereka memiliki karakter luhur dan mampu menerapkan dan mempraktikkan dalam kehidupannya. ${ }^{18}$

Pentingnya keterlibatan lembaga pendidkan untuk penanaman pendidikan karakter kepada peserta didik, membuat California Task Force Report merekomendasikan agar sistem pendidikan negara mempromosikan berbagai karakter atau nilai-nilai luhur seperti tanggung jawab. ${ }^{19}$ Dalam pendidikan Nasional di Indonesia terdapat 18 nilai-nilai yang perlu ditanamkan dalam pendidikan, yakni religius, jujur, toleransi, disiplin, kerja keras, kratif, mandiri, demograsi, rasa ingin tahu, semangat kebangsaan, cinta tanah air, menghargai prestasi, bersahabat/komunikatif, cinta damai, gemar membaca, peduli lingkungan, peduli sosial dan

\footnotetext{
${ }^{14}$ Lexy J. Moleong, Metodologi Penelitian Kualitatif, Edisi Revisi (Bandung: Remaja Rosdakarya, 2014), 6.

${ }^{15}$ Matthew B Miles and A. Michael Huberman, Analisis Penelitian Kualitatif, trans. Tjerjep Rohendi Rohidi (Jakarta: UI-Press, 1992), 16-21.

${ }^{16}$ Nashir, Pendidikan Karakter Berbasis Agama Dan Budaya, 10.

${ }^{17}$ Zubaedi, Desain Pendidikan Karakter: Konsepsi dan Aplikasinya dalam Lembaga Pendidikan Islam, Cet. 1 (Jakarta: Kencana, 2012), 14.

${ }^{18}$ Syamsul Kurniawan, Pendidikan Karakter: Konsepsi \& Implementasi Secara Terpadu di Lingkungan Keluarga, Sekolah, Perguruan Tinggi \& Masayarakat (Yogyakarta: Ar-Ruzz Media, 2013), 30.

${ }^{19}$ Francis Fukuyama, Identity: The Demand for Dignity and the Politics of Resentment (Farrar Straus and Giroux, 2018), 86,

http://gen.lib.rus.ec/book/index.php?md5=277233c5b699390635ef14e7403b6feb.
} 
tanggung jawab. ${ }^{20}$ Dengan demikian, menjadi kewajiban bagi semua lembaga pendidikan untuk mengembangkan dan menanamkan nilai-nilai karakter yang telah dirumuskan dalam pendidikan nasional.

2) Pelajaran Akidah Akhlak

Di Indonesia, lembaga pendidikan dibagi menjadi dua, yaitu lembaga pendidikan agama dan lembaga pendidikan umum. Lembaga pendidikan agama ini merupakan usaha untuk menjamin hak individu untuk memeluk dan menjalankan keyakinannya. Demikian juga dalam Islam, lembaga pendidikan Islam diakui keberadaannya dalam tubuh pendidikan nasional yang tertuang pada Undang-Undang No. 20 Tahun 2003 Tentang Sistem Pendidikan Nasional, yang menurut Haidar Daulay ${ }^{21}$ setidaknya ada tiga hal yang terkait dengan pendidikan Islam yaitu. Pertama, secara kelembagaan pendidikan madrasah diakui setara dengan sekolah. Kedua, Pendidikan Islam sebagai mata pelajaran diakui keberadaannya baik di sekolah-sekolah maupun madrasah. Ketiga, nilai (value) terdapat seperangkat nilai-nilai Islam dalam sistem pendidikan nasional.

Pendidikan Islam pada tataran kelembagaan, maka lembaga pendidikan Islam mempunyai otonomi untuk mengembangkan kurikurim agamnya, salah satunya yaitu dengan membagi mata pelajaran agama Islam kepada empat mata pelajaran, salah satunya adalah mata pelajaran akidah akhlak. Pelajaran akidah akhlak sendiri memiliki dua komponen dasar yaitu pelejaran tentang akidah Islamiyah, dan pelajaran akhlak. Pelajaran tentang Akidah Islamiyah yaitu mempelajari tentang keyakinan kepada Allah, Rasullullah, Malaikat, Hari Akhirat (Kiamat), dan Qodo dan Qadar Allah, sehingga mempunyai keyakinan yang teguh. Hal ini sesuai dengan pengertian dari akidah yang dikemukakan oleh Abdullah Al-Hamid Al-Atsari, bahwa akidah merupakan sesuatu keyakinan yang teguh dan tetap dan kuat mengenai Allah dan Rasull-Nya. ${ }^{22}$

Adapun akhlak sebagaimana dirumuskan oleh lbnu Miskwaih adalah merupakan upaya ke arah terwujudnya sikap batin yang mampu mendorong secara spontan lahirnya perbuatan-perbuatan yang bernilai baik dari seseorang. ${ }^{23}$ Akhlak, dalam konsep yang harus ditanamkan dalam pribadi manusia, menurut miskawaih setidaknya ada empat nilai mendasar yakni al-Iffat (menahan diri/self control), al-Syaja'at (keberanian), dan al-Hikmat (kebijaksanaan) serta al- Adalat (keadilan). ${ }^{24}$ Dengan demikian, maka pengertian yang diberikan oleh Miskswaih tersebut dapat dipahami bahwa dalam mata pelajaran, pelajaran akhlak adalah pelajaran yang membahas tentang tingkah laku manusia, setra upaya untuk menanamkan akhlak-akhlak terpuji kepada peserta didik.

Adapun dalam sistem pendidikan nasional, tujuan pelajaran akidah akhlak telah dirumusakan yaitu untuk menumbuh kembangkan akidah melalui pemberian, pemupukan, dan pengembangan pengetahuan, penghayatan, pengamalan, pembiasaan, serta pengalaman peserta didik

\footnotetext{
${ }^{20}$ Kementerian Pendidikan Nasional, "Panduan Pelaksanaan Pendidikan Karakter" (Badan Penelitian dan Pengembangan Pusat Kurikulum dan Perbukuan, n.d.), 8.

${ }^{21}$ Haidar Putra Daulay, Pendidikan Islam Dalam Sistem Pendidikan Nasional Di Indonesia, Edisi revisi, cetakan-3 (Jakarta: Kencana, 2012), 7.

${ }^{22}$ Abdullah Al-Hamid Al-Atsari, Al-Wajiz fi Aqidati as-Salafu as-Shalih Ahli as-Sunnah (Saudi Arabia: Dar al-Alamiyah, n.d.), 14.

${ }^{23}$ Abudin Nata, Persfektif Islam Tentang Pola Hubungan Guru-Murid Studi Pemikiran Tasawuf Al Gazali (Jakarta: Raja Grafindo Perkasa, 2001), 55.

${ }^{24}$ Harpan Reski Mulia, "Pendidikan Karakter: Analisis Pemikiran Ibnu Miskawaih," Tarbawi : Jurnal IImu Pendidikan 15, no. 1 (June 30, 2019): 43, https://doi.org/10.32939/tarbawi.v15i1.341.
} 
tentang akidah Islam, sehingga menjadi manusia muslim yang terus berkembang keimanan dan ketakwaannya kepada Allah SWT, serta, mewujudkan manusia Indonesia yang berakhlak mulia dan menghindari akhlak tercela dalam kehidupan sehari-hari, baik dalam kehidupan individu maupun sosial, sebagai manifestasi dari ajaran dan nilai-nilai akidah Islam. ${ }^{25}$

\section{B. Integrasi Pendidikan Karakter dalam Pembelajaran Akidah Akhlak}

Berdasarkan data yang diperoleh, proses intregrasi pendidikan karakter dalam pembelajaran akidah akhlak di MIN 11 Aceh Tenggara mencakup, 1) pada Kompetensi Inti; 2) Tujuan Pembelajaran; 3) Metode Pembelajaran.

1) Pada Kompetensi Inti

Dalam RPP yang digunakan guru akidah akhlak, memuat empat kompetensi inti yang harus dicapai. Karena, MIN 11 Aceh Tenggara sudah menggunakan Kurikulum 2013 (K-13) terdiri dari :

$\mathrm{KI}-1$ :Menghayati dan mengamalkan ajaran agama yang dianutnya

$\mathrm{KI}-2$ :Menghayati dan mengamalkan perilaku jujur, disiplin, tanggungjawab, peduli (gotong royong, kerjasama, toleran, damai) santun, rensponsif dan proaktif dan menunjukkan sikap sebagai bagian dari solusi atas berbagai permasalahan dalam berinteraksi secara efektif dengan lingkungan sosial dan alam serta dalam menempatkan diri sebagai cerminan bangsa dalam pergaulan dunia

KI-3:Memahami, menerapkan, dan menganalisis pengetahuan faktual, konseptual, prosedural dan metakognitif berdasarkan rasa ingin tahunya tentang ilmu pengetahuan, teknologi, seni, budaya, dan humaniora dengan wawasan kemanusiaan, kebangsaan, kenegaraan, dan peradaban terkait penyebab fenomena dan kejadian, serta menerapkan pengetahuan prosedural pada bidang kajian yang spesifik sesuai dengan bakat dan minatnya untuk memecahkan masalah

$\mathrm{KI}-4$ :Mengolah, menalar, dan menyaji dalam ranah konkret dan ranah abstrak terkait dengan pengembangan dari yang dipelajarinya di sekolah secara mandiri, bertindak secara efektif dan kreatif, serta mampu menggunakan metode sesuai kaidah keilmuan.

Proses pengintegrasian pendidikan karakter dalam pembelajaran akidah akhlak pada kompetensi initi yang dilakukan oleh guru dapat ditunjukkan sebagai temuan penelitian. Karena, kompetensi inti dalam kurikulum 2013 (K-13) merupakan terjemahan atau operasionalisasi SKL dalam bentuk kualitas yang harus dimiliki mereka, setelah menyelesaikan pendidikan pada satuan pendidikan tertentu atau jenjang pendidikan tertentu, gambaran mengenai kompetensi utama yang dikelompokkan ke dalam aspek sikap, pengetahuan, dan keterampilan (afektif, kognitif, dan psikomotor) yang harus dipelajari peserta didik untuk suatu jenjang sekolah, kelas dan mata pelajaran. Kompetensi Inti harus menggambarkan kualitas yang seimbang antara pencapaian hard skills dan soft skills.

Hal ini sejalan dengan pengertian dalam permendikbud, yaitu kompetensi inti pada kurikulum 2013 merupakan tingkat kemampuan

\footnotetext{
${ }^{25}$ Tem Penyusun, Buku Guru Akidah Akhlak (Jakarta: Kementerian Agama, 2014).
} 
untuk mencapai standar kompetensi lulusan yang harus dimiliki seorang peserta didik pada setiap tingkat kelas. ${ }^{26}$ Dengan demikian, guru akidah akhlak pada tataran ini, hanya perlu mengembangkan dan menerapkan karakter yang harus dicapai dan dimiliki oleh peserta didik pada kompetensi inti tersebut. Karena salah satu dari empat kompetensi yang harus dimiliki guru adalah kompetensi pedagogik, yakni kemampuan guru dalam pengelolaan pembelajaran peserta didik. Sebagaimana tercantum pada PP RI Nomor 74 Tahun 2008, yaitu: ${ }^{27}$

Kompetensi pedagogik sebagaimana dimaksud ada ayat (2) merupakan kemampuan guru dalam pengelolaan pembelajaran peserta didik yang sekurang-kurangnya meliputi:

a. Pemahaman wawasan atau landasan kependidikan;

b. Pemahaman terhadap peserta didik;

c. Pengembangan kurikulum atau silabus;

d. Perancangan pembelajaran;

e. Pelaksanaan pembelajaran yang mendidik dan dialogis;

f. Pemanfaatan teknologi pembelajaran;

g. Evaluasi hasil belajar; dan

h. Pengembangan peserta didik untuk mengaktualisasikan berbagai potensi yang dimilikinya.

Peraturan di atas, dapat dipahami bahwa guru ditinjau dari kompetensi pedagogik bertugas dalam pengembangan kurikulum dan silabus agar standar kompetensi dalam kurikulum dapat tercapai dan peserta didik dapat mengaktualisasikan dalam kehidupan sehari-hari. Dengan demikian, integrasi pendidikan karakter dalam pembelajaran akidah akhlak melalui kompetensi inti pada silabus, guru akidah akhlak hanya berupaya untuk mengembangkan dan menanamkan kepada peserta didik agar tertanam dan menjadi karakter dalam diri siswa.

2) Pada Tujuan Pembelajaran

Temuan penelitian tentang proses pengintegrasian pendidikan karakter dalam pembelajaran akidah akhlak, bisa dilakukan dengan merumuskan tujuan pembelajaran dari tema yang dipelajari pada mata pelajaran akidah akhlak. Melalui tujuan pembelajaran ini, guru akidah akhlak merumuskan tujuan pembelajaran yang akan dicapai oleh peserta didik berkenaan dengan karakter yangg diharapkan.

Ditinjau dari segi muatannya akidah akhlak mempunyai tujuan yang sama dengan pendidikan karakter. Hal ini senada dengan pendapat Zubeid yang mengatakan bahwa dalam kaitannya dengan pendidikan akhlak, terlihat bahwa pendidikan karakter mempunyai orientasi yang sama, yaitu pembentukan karakter. Perbedaan bahwa pendidikan akhlak terkesan timur dan Islam, sedangkan pendidikan karakter terkesan barat dan sekuler, bukan alasan untuk dipertentangkan. ${ }^{28}$

\footnotetext{
${ }^{26}$ Menteri Pendidikan Dan Kebudayaan Republik Indonesia, (2016), Peraturan Menteri Pendidikan dan Kebudayaan Republik Indonesia Nomor 24 Tahun 2016 Tentang Kompetensi Inti dan Kompetensi Dasar Pelajaran Pada Kurikulum 2013 Pada Pendidikan Dasar Dan Pendidikan Menengah. Bab II Pasal 2. Kementerian Pendidikan dan Kebudayaan, "Badan Penelitian Dan Pengembangan | Kementerian Pendidikan Dan Kebudayaan," accessed January 7, 2019, http://litbang.kemdikbud.go.id/content/02_\%20SKL\%20MAPEL\%20SD-MI.pdf.

27 "PP_74_Tahun_2008.Pdf," accessed January 7, 2019, https://unnes.ac.id/wpcontent/uploads/PP_74_Tahun_2008.pdf Pasal 3.

${ }^{28}$ Zubaedi, Desain Pendidikan Karakter, 64.
} 
Otoritas mata pelajaran akidah aklak pada pendidikan dibawah nuangan menteri agama merupakan suatu keniscayaan untuk melangsungkan pembelajaran tersebut. Namun disisi lain bahwa segala bentuk pendidikan baik dibawah naungan Kementerian Pendidik dan Kebudayaan maupun Kementerian Agama harus mengacu pada tujuan dan fungsi yang sama sebagaimana dirumuskan dalam tujuan pendidikan nasional, yaitu:

"Pendidikan nasional berfungsi mengembangkan kemampuan dan membentuk watak sertaperadaban bangsa yang bermartabat dalam rangka mencerdaskan kehidupan bangsa, bertujuanuntuk berkembangnya potensi peserta didik agar menjadi Manusia yang beriman dan bertakwakepada Tuhan Yang Maha Esa, berakhlak mulia, sehat, berilmu, cakap, kreatif, mandiri, danmenjadi warga negara yang demokratis serta bertanggung jawab."29

Dengan demikian pengintegrasian pendidikan karakter dalam pembelajaran akidah akhlak pada tujuan pembelajaran, merupakan keharusan bagi seorang guru, karena sebagaimana tujuan pendidikan nasional yang harus dicapai diantaranya adalah menjadi manusia yang beriman dan bertakwa kepada Tuhan Yang Maha Esa dan berakhlak mulia. Maka bagi seorang guru seyogianya merumuskan tujuan pembelajan yang terintegrasi dengan pendidikan karakter.

Di samping itu, akidah akhlak yang memang dirancang pada proses pembelajaran bertujuan agar memberikan sumbangsih terhadap peserta didik bersikap religius dalam arti taat kepada Allah dan berakhlak mulia. Hal ini tercantum sebagaimana tujuan tertinggi yang hendak dicapai oleh pendidikan Islam ialah kesempurnaan manusia dalam merealisasikan hidup dan penghidupannya untuk memperoleh ridah Allah melalui kegiatan berilmu dan beramal. ${ }^{30}$

3) Pada Metode Pembelajaran

Temuan penelitian yang terakhir dalam upaya yang dapat dilakukan oleh guru akidah akhlak untuk pengintegrasian pendidikan karakter dalam pembelajaran akidah akhlak adalah metode pembelajaran. Metode pembelajaran itu sendiri diartikan sebagai teknik penyajian yang dikuasai oleh seorang guru untuk menyajikan materi pelajaran kepada murid di dalam kelas baik secara individu atau secara kelompok, agar materi pelajaran dapat diserap, dipahami dan dimanfaatkan oleh murid dengan baik. ${ }^{31}$ Pengertian ini memberikan pamahaman bahwa metode pengajaran merupakan cara yang dilakukan oleh guru agar peserta didik dapat memahami materi pelajaran dan pelajaran tersebut dapat dimanfaatkan atau berdadya guna bagi peserta didik.

Definisi yang lebih luas dikemukakan oleh Omar Mohammad ${ }^{32}$, ia menyebutkan bahwa:

"Metode mengajar bermakna segala segi segi kegiatan yang

terarah yang dikerjakan oleh guru dalam rangka kemestian-

kemestian mata pelajaran yang diajarkannya, ciri-ciri

\footnotetext{
29"UU2003.Pdf," n.d., 3 BAB II, Pasal 3.

${ }^{30}$ Siddik, Konsep Dasar IImu Pendidikan Islam, 49.

${ }^{31}$ Abdurrahman Ginting, Esensi Praktis Belajar dan Pembelajaran (Bandung: Pustaka Setia, 2008), 42.

${ }^{32}$ Omar Muhammad Al-Toumy Al-Syaibany, Falsafatut Tarbiyah Al Islamiyah, trans. Hasan Langgulung, I (Jakarta: Bulan Bintang, 1979), 553.
} 
perkembangan murid-muridnya, dan suasana alam sekitarnya dan tujuan menolong murid-muridnya untuk mencapai proses belajar yang diinginkan dan perubahan yang dikehendaki pada tingkah laku mereka. Selanjutnya menolong mereka memperoleh maklumat, pengetahuan, keterampilan, kebiasaan, sikap, minat dan nilai-nilai yang diinginkan.

Dengan demikian metode pembelajan yang bertujuan untuk menolong peserta didik memahami pelajaran agar mempunyai pengetahuan, keterampilan, kebiasaan dan sikap menjadikan pengintegrasian pendidikan karakter dalam pembelajaran akidah akhlak dapat dilakukan. Disamping itu ada asas-asas pelaksanaan metode pendidikan dalam pendidikan Islam. Sebagaimana Muhaimin dan Abdul Mujib menyatakan bahwa ada 16 asas dalam pelaksanaan metode pembelajaran $^{33}$, yaitu: 1) Asas motivasi; 2) Asas aktivitas; 3) Asas apersepsi; 4) Asas peragaan; 5) Asas ulangan; 6) Asas korelasi; 7) Asas konsentrasi; 8) Asas individualisasi; 9) Asas sosialisasi; 10) Asas evaluasi; 11) Asas kebebasan; 12) Asas lingkungan; 13) Asas globalisasi; 14) Asas pusat-pusat minat; 15) Asas ketauladanan; 16) Asas pembiasaan.

Selanjutnya Saleh yang dikutip Muhaimin dan Abdul Mujib menjelaskan bahwa asas metode pendidikan dalam penyampaian pelajaran adalah menghindari ketegangan dan suasana yang menakutkan pada anak didik, dengan menggunakan pelatihan-pelatiah yang intesif, memberi contoh dan tingkah laku yang baik, partisipasi yang memadai pada anak didik, serta memandang bahwa segala aktivitas yang dilakukan merupakan ibadah, asal berangkat dengan Bismillah sebagai penghambaan tugas wakil Allah Swt. ${ }^{34}$

Metode pembelajaran mempunyai peran penting dalam pengintegrasian pendidikan karakter, sebagaimana tercermin pada asas metode di atas bahwa metode itu harus dapat memberikan pembiasaan dan memberi contoh dan tingkah laku yang baik bagi peserta didiknya. Hal ini menunjukkan bahwa metode pembelajaran yang dipakai guru juga merupakan bagian dari pendidikan karakter.

Alquran sebagai sumber utama bagi Islam pada konteks pengajaran juga menggunakan metode-metode yang bervariasi agar mudah dipahami dan diamalkan oleh pemeluknya sebagai contohnya Alquran menawarkan metode kisah agar fikiran manusia bernalar sebagaimana tergambar pada surah Al-'Araf ayat 176.

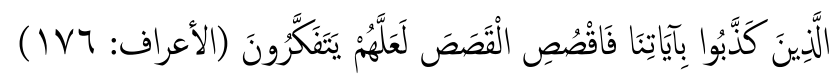

Artinya : “........orang-orang yang mendustakan ayat-ayat kami. Maka Ceritakanlah (kepada mereka) kisah-kisah itu agar mereka berfikir." ${ }^{35}$

Dalam ayat lain Alquran juga memberikan contoh metode demonstrasi, sebagaimana diriwayatkan bahwa nabi Musa mengikuti

\footnotetext{
${ }^{33}$ Muhaimin and Abdul Mujib, Pemikiran pendidikan Islam: kajian filosofis dan kerangka dasar operasionalisasinya (Bandung: Trigenda Karya, 1993), 234-40.

${ }^{34}$ Muhaimin and Mujib, 241.

${ }^{35}$ Departemen Agama Republik Indonesia, Mushaf Al-Quran Terjemah, ed. Abdul Aziz and Abdur Rauf, 2002nd ed. (Jakarta: Al-Huda Kelompok Gema Insani, 2005), 174.
} 
nabi Haidir untuk belajar dan mnimba ilmu kepadanya, kemudian dalam perjalanan mereka nabi Khidir melobangi perahu yang mereka naiki, kemudian juga nabi Haidir membunuh anak yang masih remaja dan lain sebagaimanya, hal ini dapat dipahami bahwa nabi Haidir langsung mendemonstrasikan pelajaran tersebut. Demikian yang tergambar dalam surah Al-Kahfi ayat 66.

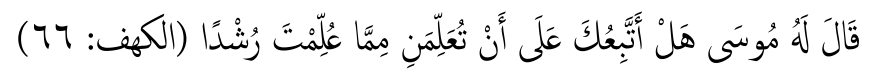

Artinya : Musa berkata kepada Khidhr: "Bolehkah aku mengikutimu supaya kamu mengajarkan kepadaku ilmu yang benar di antara ilmu-ilmu yang telah diajarkan kepadamu?"36

Banyak lagi metode lain yang dicontohkan dalam Alquran seperti metode keteladan yang digambar pada surah Al-Ahzab ayat 21, metode ceramah pada surah Thaaha ayat 25-28, metode tanya jawab pada surah As-Sffat ayat 100-108 dan lain sebagainya, yang kesemuanya itu menunjukkan bahwa metode pembelajaran sangatlah penting dalam pembelajaran.

Bertitik tolak dari pengertian dan asas-asas serta ayat-ayat Alquran tentang metode pembelajaran di atas dapatlah disimpulkan bahwa metode pembelajaran menjadi suatu terobosan bagi guru akidah akhlak untuk mengintegrasikan pendidikan karakter dalam pembelajaran akida akhlak.

\section{Kesimpulan}

Berdasarkan hasil penelitian dan pembahasan, serta analisis yang telah dilakukan tentang proses pengintegrasian pendidikan karakter dalam pembelajaran akidah akhlak di MIN 11 Aceh Tenggara dapat diambil kesimpulan sebagai berikut:

1) Pada Kompetensi Inti hanya perlu dikembangkan dan diklasifikasikan karakter yang ada padanya.

2) Pada tujuan pembelajaran yang akan dicapai pada materi yang diajarkan.

3) Melalui metode pembelajaran pada metode pembelajaran ini guru memilih metode yang menunjang pada penanaman karakter yang telah dirumuskan pada tujuan pembelajaran.

\section{Daftar Pustaka}

Afandi, Rifki. "Integrasi Pendidikan Karakter Dalam Pembelajaran IPS Di Sekolah Dasar." PEDAGOGIA: Jurnal Pendidikan 1, no. 1 (February 1, 2011): 8598. https://doi.org/10.21070/pedagogia.v1i1.32.

Al-Atsari, Abdullah Al-Hamid. Al-Wajiz fi Aqidati as-Salafu as-Shalih Ahli asSunnah. Saudi Arabia: Dar al-Alamiyah, n.d.

Daulay, Haidar Putra. Pendidikan Islam Dalam Sistem Pendidikan Nasional Di Indonesia. Edisi revisi, Cetakan-3. Jakarta: Kencana, 2012.

Departemen Agama Republik Indonesia. Mushaf Al-Quran Terjemah. Edited by Abdul Aziz and Abdur Rauf. 2002nd ed. Jakarta: Al-Huda Kelompok Gema Insani, 2005.

Dianti, Puspa. "Integrasi Pendidikan Karakter Dalam Pembelajaran Pendidikan Kewarganegaraan Untuk Mengembangkan Karakter Siswa." Jurnal

\footnotetext{
${ }^{36}$ Departemen Agama Republik Indonesia, 302.
} 
Pendidikan Ilmu Sosial 23, no. 1 (2014). https://doi.org/10.17509/jpis.v23i1.2062.

Fukuyama, Francis. Identity: The Demand for Dignity and the Politics of Resentment. Farrar Straus and Giroux, 2018. http://gen.lib.rus.ec/book/index.php?md5=277233c5b699390635ef14e740 3b6feb.

Ginting, Abdurrahman. Esensi Praktis Belajar dan Pembelajaran. Bandung: Pustaka Setia, 2008.

Hermino, Agustino. Manajemen Kurikulum berbasis Karakter: Konsep, Pendekatan, dan Aplikasi. Bandung: Alfabeta, 2014.

Kebudayaan, Kementerian Pendidikan dan. "Badan Penelitian Dan Pengembangan | Kementerian Pendidikan Dan Kebudayaan." Badan Penelitian dan Pengembangan | Kementerian Pendidikan dan Kebudayaan. Accessed January 2019. http://litbang.kemdikbud.go.id/content/02_\%20SKL\%20MAPEL\%20SDMl.pdf.

Kementerian Pendidikan Nasional. "Panduan Pelaksanaan Pendidikan Karakter." Badan Penelitian dan Pengembangan Pusat Kurikulum dan Perbukuan, n.d.

Khusniati, M. "Pendidikan Karakter Melalui Pembelajaran IPA." Jurnal Pendidikan IPA Indonesia 1, no. 2 (2012). https://doi.org/10.15294/jpii.v1i2.2140.

Kurniawan, Syamsul. Pendidikan Karakter: Konsepsi \& Implementasi Secara Terpadu di Lingkungan Keluarga, Sekolah, Perguruan Tinggi \& Masayarakat. Yogyakarta: Ar-Ruzz Media, 2013.

Lestyarini, Beniati. "Penumbuhan Semangat Kebangsaan Untuk Memperkuat Karakter Indonesia Melalui Pembelajaran Bahasa." Jurnal Pendidikan Karakter 0, no. 3 (2012): 340-54. https://doi.org/10.21831/jpk.v0i3.1250.

Miles, Matthew B, and A. Michael Huberman. Analisis Penelitian Kualitatif. Translated by Tjerjep Rohendi Rohidi. Jakarta: UI-Press, 1992.

Moleong, Lexy J. Metodologi Penelitian Kualitatif. Edisi Revisi. Bandung: Remaja Rosdakarya, 2014.

Muhaimin, and Abdul Mujib. Pemikiran pendidikan Islam: kajian filosofis dan kerangka dasar operasionalisasinya. Bandung: Trigenda Karya, 1993.

Mulia, Harpan Reski. "Pendidikan Karakter: Analisis Pemikiran Ibnu Miskawaih." Tarbawi: Jurnal Ilmu Pendidikan 15, no. 1 (June 30, 2019): 39-51. https://doi.org/10.32939/tarbawi.v15i1.341.

Nashir, Haedar. Pendidikan Karakter Berbasis Agama Dan Budaya. Yogyakarta: Multi Presindo, 2013.

Nata, Abudin. Persfektif Islam Tentang Pola Hubungan Guru-Murid Studi Pemikiran Tasawuf Al Gazali. Jakarta: Raja Grafindo Perkasa, 2001.

Omar Muhammad Al-Toumy Al-Syaibany. Falsafatut Tarbiyah Al Islamiyah. Translated by Hasan Langgulung. I. Jakarta: Bulan Bintang, 1979.

Pamilangan, Buhari. "Integrasi Pendidikan Karakter Dalam Pembelajaran Aqidah Akhlak." Istiqra' : Jurnal Pendidikan Dan Pemikiran Islam 6, no. 1 (2018). https://www.umpar.ac.id/jurnal/index.php/istiqra/article/view/467.

"PP_74_Tahun_2008.Pdf." Accessed January 7, 2019. https://unnes.ac.id/wpcontent/uploads/PP_74_Tahun_2008.pdf.

Siddik, Dja'far. Konsep Dasar IImu Pendidikan Islam. Edisi Revisi, Cet. 1. Bandung: Citapustaka Media Perintis, 2011.

Tem Penyusun. Buku Guru Akidah Akhlak. Jakarta: Kementerian Agama, 2014.

Triyono, Sulis. "Pengintegrasian Pendidikan Karakter dalam Pembelajaran Bahasa Jerman." Jurnal Pendidikan Karakter 0, no. 3 (2012): 269-79. https://doi.org/10.21831/jpk.v0i3.1250. 
"UU20-2003-Sisdiknas.Pdf." Accessed May 4, 2020. https://www.unpad.ac.id/wpcontent/uploads/2012/10/UU20-2003-Sisdiknas.pdf.

Zaini, Zaini, and Roni Ramlan. "Penguatan Pendidikan Aqidah Anak Dari Penyimpangan Budaya Online." TADRIS: Jurnal Pendidikan Islam 14, no. 2 (December 26, 2019): 201-14. https://doi.org/10.19105/tjpi.v14i2.2736.

Zubaedi. Desain Pendidikan Karakter: Konsepsi dan Aplikasinya dalam Lembaga Pendidikan Islam. Cet. 1. Jakarta: Kencana, 2012.

Zuchdi, Darmiyati, Zuhddan Kun Prasetya, and Muhsinatun Siasah Masruri. Model Pendidikan Karakter: Terintegrasi Dalam Pembelajaran Dan Pengembangan Kultur Sekolah. Yogyakarta: Multi Presindo, 2013. 